\title{
Escola Itinerante: espaço de disputa e contradição ${ }^{1}$
}

\section{Itinerant School: space of dispute and contradiction}

\author{
Marlene Lucia Siebert Sapelli
}

\begin{abstract}
RESUMO
O objetivo deste trabalho é apresentar a experiência de escola feita pelo Movimento dos Trabalhadores Rurais Sem Terra - MST, no Paraná, nos acampamentos, a partir de 2003, culminando com a construção da proposta dos Complexos de Estudo, implementada a partir de 2013. O trabalho foi feito por meio de análise de bibliografias e de pesquisa de campo (análise documental, entrevistas, participação em processos de formação continuada). Pudemos perceber a construção de uma proposta contra-hegemônica, produzida num processo de autogestão da classe trabalhadora, sustentando-se em elementos que exigem alterações da forma e do conteúdo da escola, bem como, a ruptura com o modelo oficial do Estado. Também pudemos observar um processo de continuidade e descontinuidade na implementação da proposta. Para discutir e explicitar tais questões, organizamos o texto em duas partes: na primeira contextualizamos a criação das escolas itinerantes do Paraná e, a seguir, caracterizamos a suas propostas, especialmente, a partir da implementação da proposta dos Complexos de Estudo, em 2013.
\end{abstract}

Palavras-chave: MST; Paraná; proposta pedagógica.

\begin{abstract}
The aim of this paper is to present the experience of the school carried out by the Landless Rural Workers Movement, the MST, Paraná, in the encam-

DOI: $10.1590 / 0104-4060.39834$

1 Pesquisa financiada pelo Conselho Nacional de Desenvolvimento Científico e Tecnológico (CNPq) junto ao Programa de Pós-Graduação em Educação (PPGE) da Universidade Federal de Santa Catarina (UFSC) (2011-2013) e, após ampliação do objeto da pesquisa, novamente pelo CNPq em 2014 e 2015 a partir do Projeto de Pesquisa Continuada apresentado também junto à Pró-Reitoria de Pesquisa e Pós-Graduação (PROPESP) da Universidade Estadual do Centro-Oeste (Unicentro) (Guarapuava-PR).

2 Universidade Estadual do Centro-Oeste. Guarapuava, Paraná, Brasil. Setor de Humanas, Letras e Artes. Rua Padre Salvatore Renna. CEP: 85.015-430.
\end{abstract}


pments, from 2003, culminating in the construction of the proposed Studies Complexes, implemented from 2013. The work was done by bibliographic analysis and field research (document analysis, interviews, participation in continuing education processes). We could notice the construction of a counterhegemonic proposal, produced in a self-management working class process, sustaining it on elements that require changes to the form and content of the school, as well as, the break with the official model of the State. We also observed a process of continuity and discontinuity in the proposal implementation. To discuss and explain these issues, we organized the article into two parts: in the first we contextualise the creation of itinerant schools of Paraná and then we characterise their proposal, especially since the implementation of the proposed Studies Complexes, in 2013.

Keywords: MST; Paraná; pedagogical proposal.

\section{Introdução}

Todos os fenômenos sociais são marcados pela contradição, desenvolvem-se, portanto, como unidades de contrários. Sendo assim, para compreendê-los partimos do seu conteúdo interno, das suas relações com outros fenômenos, segundo Tsé-Tung (2001). Para o autor, “[...] as contradições existem no processo de desenvolvimento de todos os fenômenos; [...] e no processo de desenvolvimento de cada fenômeno, o movimento contraditório existe do começo ao fim" (TSÉ-TUNG, 2001, p. 46), portanto, há uma universalidade e uma particularidade na contradição. Não há para ele fenômeno sem contradição.

É com esse pressuposto que investimos esforços na análise de um fenômeno social: a educação, mais especificamente o processo educativo que ocorre nas escolas itinerantes do Paraná, que carrega várias contradições: entre o velho e o novo jeito de educar; entre capital e trabalho; entre proprietários e não proprietários; entre movimento social e Estado; entre processos de regulação e de autogestão.

Nos registros das experiências escolares da história da educação brasileira, em geral, pouca visibilidade se dá àquelas feitas pela classe trabalhadora, em processos de autogestão, na perspectiva contra-hegemônica, rompendo com o oficialismo do Estado. Este artigo tem por objetivo apresentar uma dessas experiências - feita pelo Movimento dos Trabalhadores Rurais Sem Terra (MST), no Paraná, nas escolas itinerantes, ou seja, em escolas de acampamento, que carrega elementos construídos desde os anos 1980, quando o Movimento iniciou um processo de engendramento da sua proposta de escola, acumulando até os dias de hoje muitos avanços, desafios, contradições e tensões. 
O trabalho foi feito por meio dos seguintes encaminhamentos metodológicos: análise bibliográfica; coleta e análise de documentos das escolas itinerantes (Projeto Político-Pedagógico, Plano de Estudos, relatórios de encontros, resoluções); entrevistas com pais, estudantes, coordenadores das escolas e representantes do setor estadual de educação do MST, bem como participação em processos de formação continuada de educadores das escolas em questão, com análises posteriores. Para realizar a maioria dos encaminhamentos metodológicos foram feitas visitas a todas as escolas envolvidas na pesquisa, o que possibilitou uma análise das questões a partir da materialidade das mesmas, explicitando não só as questões da escola, mas as questões da vida produzida nos acampamentos que interferem diretamente no conteúdo e na forma da escola.

Para discutir e explicitar tais questões, organizamos o texto em duas partes: na primeira contextualizamos a criação das escolas itinerantes do $\mathrm{Pa}$ raná no processo de instituição do Movimento dos Trabalhadores Rurais Sem Terra e, a seguir, caracterizamos as suas propostas, especialmente, a partir da implementação da proposta dos Complexos de Estudo, em 2013, indicando no processo de elaboração e de implementação as dificuldades encontradas e os avanços conseguidos, finalizando as discussões com uma reflexão sobre o que esse processo representa quando se trata de autogestão e de controle social.

\section{O MST e a criação das escolas itinerantes}

Apesar de o MST ter sido criado oficialmente em 1984 há precedentes históricos importantes que contribuíram para esse fato: os processos migratórios da segunda metade do século XIX e do início do século XX, tanto da Europa quanto internos; entre 1950 e 1960, a fundação das primeiras Ligas Camponeses, inclusive no Paraná, e da ULTAB (União dos Lavradores e Trabalhadores Agrícolas do Brasil); a fundação de muitos sindicatos rurais; ações em outros estados, como por exemplo, no Rio Grande do Sul, com a organização de muitos acampamentos e o conflito entre índios e posseiros, em 1979, na Reserva de Nonoai e, em 1981, na Encruzilhada Natalino e a construção de usinas hidrelétricas. (SAPELLI, 2013).

O MST é um movimento social que teve para sua constituição várias influências, partidárias, sindicais e até religiosa, por meio da Teologia da Libertação, e que tem muitos enfrentamentos com a classe dominante, especialmente representados pela UDR (União Democrática Ruralista), que 
[...] criada em 1985, constituída por um grupo de fazendeiros violentos e conservadores, intensificou esforços para desmobilizar a igreja e as entidades que apoiavam os trabalhadores rurais na luta pela terra, posicionando-se na Assembleia Constituinte em defesa da propriedade privada. (SAPELLI, 2013, p. 39).

$\mathrm{Na}$ luta pela mudança da estrutura fundiária brasileira, o Movimento promoveu muitas ocupações e muitos confrontos, dos quais resultou, de 1979 a 2006, no Paraná, por exemplo, a criação de 300 assentamentos para 19.066 famílias em uma área de 402.052 hectares. (DATALUTA, 2006). Isso pode não ter alterado significativamente a estrutura fundiária do Estado, que continua com altos índices de concentração de terra, mas promoveu a mudança de vida de todas essas famílias e, em alguns casos, da própria economia de pequenos municípios, como é o caso de Rio Bonito do Iguaçu-PR.

Explicitando o contexto, do qual emerge o MST, podemos indicar que as contradições centrais que se apresentam são entre trabalho e capital e, em decorrência, entre proprietários e não proprietários, uma vez que o processo de produção engendrado nos acampamentos se dá em áreas de ocupação, numa luta pela propriedade da terra, ou seja, num processo de confronto entre proprietários e não proprietários. Além disso, a produção da vida feita nesses espaços também é caracterizada pelo trabalho assalariado, pela precarização do trabalho, pela exploração de uns sobre outros e, ao mesmo tempo, pelo esforço em reunir produtores livremente associados, buscando igualdade substantiva. (MÉSZÁROS, 2007, p. 229).

Desde sua criação oficial, em 1984, o MST vem lutando pela Reforma Agrária e a essa luta agrega outras: por educação, por saúde, por moradia, por trabalho e renda. Na luta pela educação tem traçado estratégias e feito movimento em várias frentes, principalmente, em Educação de Jovens e Adultos; em processos de formação inicial e continuada de educadores; em processos de formação profissional. Nessa luta, uma das questões pautadas pelo Movimento, no Estado do Paraná, mais fortemente a partir de 2003, foi pelo direito de ter escolas nos acampamentos. Essa luta teve antecedentes, inclusive em outros estados.

Segundo Camini (2009), as primeiras experiências de criar escolas em acampamentos aconteceram antes mesmo da criação oficial do MST, em 1984, pois em 1982, ainda segundo Camini (2009), na Encruzilhada Natalino houve um acampamento à beira da estrada, com 600 famílias, onde se construiu a primeira escola em acampamento, que foi legalizada em abril de 1984, no Assentamento Nova Ronda Alta. Foi essa a primeira experiência de escola em acampamento no Brasil. A segunda foi na Fazenda Annoni, município de Sarandi-RS, em 1985. 
Apesar de mostrar que essas foram as duas primeiras experiências, nenhuma delas foi legalizada em acampamento. Somente em 1996, segundo a autora, é que o Conselho Estadual de Educação do Rio Grande do Sul, por meio do Parecer 1.313/96, com base no artigo da Lei Federal $n^{\circ} 5.692 / 71$, aprovou o funcionamento da escola itinerante como 'experiência pedagógica', por dois anos. Essa experiência foi prorrogada por duas vezes pelas Resoluções 237/98 e 247/99.

No Paraná, esse processo iniciou com a experiência feita em 1999 (PR), em um acampamento, em frente ao Palácio do Iguaçu, em Curitiba-PR, em protesto às políticas do Governo Jaime Lerner em relação à Reforma Agrária, onde foi organizada uma escola que funcionou durante 14 dias. A experiência foi batizada de Escola Itinerante. (MST, 2008a). Outra experiência foi a escola que funcionou, em 1996, no Acampamento do Buraco, no processo de ocupação da Fazenda Pinhal Ralo, segundo depoimento ${ }^{3}$ de um dos coordenadores do Coletivo Estadual de Educação/PR. Uma das experiências decisivas para a instituição das escolas itinerantes foi a realizada no Acampamento $1^{\circ}$ de Maio, em 2003, com a criação da Escola Itinerante Paulo Freire. Podemos considerar essa experiência o marco do processo de criação dessas escolas no Paraná. (SAPELLI, 2013).

Depois disso, em 2003, o Conselho Estadual de Educação (CEE) aprovou o funcionamento das escolas itinerantes no Paraná, por meio do Parecer 1.012, de 8 de dezembro, e da Resolução 614, de 17 de fevereiro de 2004, da Secretaria de Estado da Educação (SEED/PR), como 'experiência pedagógica', por dois anos e, em 2005, sob o Parecer 735/05, renovada por mais 3 anos.

Tanto no processo de luta pela terra como no processo de luta pela escola, o Estado assumiu, em relação aos trabalhadores vinculados ao MST, posição de contraposição, explicitando seu caráter de classe, pois promoveu ações para potencializar a integração ao grande movimento do capital, na reorganização da produção, também no campo, bem como criando dificuldades para a abertura das escolas itinerantes ou, mesmo aprovando-as em um momento posterior, garantindo apenas condições precárias para seu funcionamento. Isso revela mais uma das contradições no processo de criação das escolas itinerantes, entre o movimento social e o Estado.

A criação dessas escolas teve como objetivo "[...] atender as crianças, adolescentes, jovens e adultos em situação de itinerância, enquanto estão acampados lutando pela desapropriação das terras improdutivas e implantação do assentamento". (MST, 2008b, p. 88).

A escola itinerante tem como metas: ser uma escola do Movimento, vinculada e comprometida com a luta pela Reforma Agrária e da classe trabalhadora; formar para a atualidade; promover uma educação voltada para a formação 
omnilateral; garantir apropriação dos conhecimentos produzidos socialmente; democratizar as relações na escola; privilegiar na metodologia de ensino processos de cooperação, trabalho e participação; promover integração entre escola e comunidade. (MST, 2006, não paginado).

O número de Escolas Itinerantes - EI no Paraná é inconstante, pois acompanha a itinerância da própria luta pela terra. Segundo Sapelli (2013), em 2004, eram 6 escolas itinerantes; em 2005, eram 9; de 2006 a 2009 eram 11 escolas. (MST, 2008b). Em 2010 e 2011 eram 10, em 2012 e 2013 eram 9 escolas. Nesse período houve um decréscimo no número de educandos, que está relacionado à diminuição do número de moradores nos acampamentos. Todas essas escolas fazem parte da rede estadual, dada sua natureza de itinerância, podendo, por isso, mudar de município. Isso exige sua vinculação à escola-base que é o Colégio Estadual Iraci Salete Strozak (situado no Assentamento Marcos Freire, em Rio Bonito do Iguaçu-PR), onde ficam arquivados os documentos dos educandos das mesmas e é ela quem faz o cadastramento, expede documentos dos educandos e dá suporte pedagógico às EI.

\section{A construção da proposta pedagógica das escolas itinerantes}

Ser uma escola inserida na luta, portanto, num processo contra-hegemônico, impõe às escolas itinerantes e suas comunidades a exigência de construir uma proposta pedagógica que responda a esse processo. Pautado nisso, o Movimento tem buscado, desde os anos 1980, acumular aprendizagens, na perspectiva de construir tal proposta. Nos anos 1980, logo após a Ditadura Militar, foi definindo o conjunto de princípios filosóficos e pedagógicos que orientam sua proposta. Segundo Sapelli (2013), os princípios filosóficos representam, para o Movimento, a tentativa de expressar a concepção de sociedade, de ser humano e de educação. São eles: educação para a transformação social; educação para o trabalho e cooperação; educação voltada para as várias dimensões do ser humano ${ }^{4}$; educação para/com valores humanistas e socialistas ${ }^{5}$; educação como

4 Ao indicar uma formação omnilateral, o Movimento enfatiza algumas dimensões: político-ideológica, organizativa, técnico-profissional, do caráter ou moral, cultural, estética, afetiva, religiosa e outras. (MST, 2005).

5 Ao indicar valores humanistas/socialistas, o Movimento enfatiza: sentimento de indignação; companheirismo; solidariedade; busca de igualdade, respeito, direção coletiva; disciplina, força para militância; exercício da crítica e autocrítica; sensibilidade ecológica; criatividade; iniciativa; amor e outros. (MST, 2005). 
processo permanente de formação/transformação humana. Os princípios pedagógicos representam a tentativa de expressar o "[...] jeito de fazer e de pensar a educação, para concretizar os próprios princípios filosóficos. [...] incluindo, especialmente, a reflexão metodológica dos processos educativos". (MST, 2005, p. 160). São eles: relação entre teoria e prática; combinação entre processos de ensino e de capacitação; a realidade como base da produção do conhecimento; conteúdos formativos socialmente úteis; educação para o trabalho e pelo trabalho; vínculo orgânico entre processos educativos e políticos; vínculo orgânico entre processos educativos e econômicos; vínculo orgânico entre educação e cultura; gestão democrática; auto-organização dos estudantes; criação de coletivos pedagógicos e formação permanente dos(as) educadores(as); atitude e habilidades de pesquisa.

Dos anos 1980 a 2010, o MST, no Paraná, teve como referência bastante significativa para sua proposta os fundamentos encontrados em Paulo Freire, especialmente, no que se refere ao trabalho com os "temas geradores". No Dossiê MST Escola (uma coletânea de documentos do MST), há um documento intitulado Como fazer a escola que queremos: o planejamento (Caderno de Educação, n. 6, de 1995), no qual se afirma que a adoção desse trabalho nasceu da preocupação de educadores progressistas em criar alternativas para tornar o processo educativo mais voltado aos interesses e necessidades da classe trabalhadora. Entende-se que os temas geradores são questões da realidade que contribuem para desenvolver os conteúdos e as didáticas e que são geradores porque criam a necessidade de novos conhecimentos. Para definição dos temas geradores sugere-se um diagnóstico da realidade.

Mesmo adotando essa perspectiva, o Movimento já estudava, na mesma época, um autor russo, chamado Pistrak, e acabou incorporando desse autor elementos importantes, especialmente sobre a auto-organização dos estudantes.

Fundamentados, principalmente, em Paulo Freire, Pistrak e Vygotsky, o Movimento construiu a partir de 2005, para as escolas de acampamento e para a escola-base, a proposta dos Ciclos de Formação Humana ${ }^{6}$. A autorização para implantação da proposta, como experimento, foi feita por meio do Parecer do CEE/PR 117, de 11 de fevereiro de 2010, e da Resolução 3.922/10, pelo prazo de cinco anos. A proposta tinha/tem como elementos centrais: a organização das turmas em ciclos, a adoção da área como princípio metodológico, o conselho participativo, o parecer descritivo e a gestão que busca a participação ampliada da comunidade.

6 Para conhecer mais detalhadamente essa proposta ver Sapelli (2013); Cericato (2008); Leineker (2012). 
Quase concomitantemente a esse processo, em 2009, quando o Movimento, contando com a participação de educadores da Educação Básica e de algumas universidades, estava construindo alguns cadernos para registrar a experiência vivida nas escolas vinculadas a ele, percebeu a necessidade de incorporar alguns elementos, no sentido de avançar, principalmente, em relação ao planejamento a partir das questões da realidade e da auto-organização dos estudantes. A partir disso, em 2010, com a assessoria de Luiz Carlos de Freitas (da Unicamp) e de Roseli Salete Caldart (do Iterra/MST), o Movimento passou a reelaborar sua proposta pedagógica, incorporando mais elementos da pedagogia soviética ${ }^{7}$, tendo seu início de implementação em 2013.

O processo de reelaboração da proposta, que ocorreu de 2010 a 2012, foi feito com várias dificuldades. Segundo Sapelli (2013), podem ser indicadas: dificuldades de financiamento para a realização dos trabalhos da equipe de elaboração da proposta que envolvia educadores das escolas de acampamento e escola-base, educadores de Universidades e assessores; mudança de especialistas que faziam parte da equipe de elaboração, o que causou rupturas e descontinuidades; centralidade do processo em um assessor, no caso professor Luiz Carlos de Freitas, que detinha a maior parte do conhecimento sobre a proposta; domínio restrito por parte de alguns integrantes da proposta de elaboração; dificuldade de reproduzir recriando a proposta soviética; condições de trabalho que prolongaram muito o processo; manter a teoria do conhecimento, no caso, o materialismo histórico dialético como referência, uma vez que nem todos os envolvidos a tinham como referência.

O novo Plano de Estudos produzido nesse processo, para as escolas em questão, está baseado na concepção de educação defendida pelo Movimento desde os anos 1980, que consiste no entendimento de que

[...] a educação é pensada no plano da formação humana e não apenas da instrução ou mesmo do acesso ao conjunto da produção cultural de uma sociedade. Educação é, em síntese, um processo intencional de busca do desenvolvimento multilateral do ser humano. (FREITAS; SAPELLI; CALDART, 2013, p. 12).

Há uma preocupação com a formação humana em todas as dimensões e, consequentemente, a formação do militante no processo de luta pela Reforma

7 Para aprofundar o entendimento sobre a pedagogia soviética, do período posterior à Revolução de 1917, ver Pistrak (2003, 2009); Shulgin (2013). 
Agrária. Para isso, adota-se como matriz principal a vida e decorrente dela o trabalho, a cultura, a história, a organização coletiva e a luta. É marco dessa proposta construir um projeto de escola que supere a sala de aula como centro do processo, tornando-a tática importante num projeto estratégico que visa a emancipação humana. Isso só é possível em espaços em que os sujeitos enfrentem o próprio Estado, que tem caráter classista (dominante), e façam autogestão dos processos de educação.

A certeza da transformação da educação não está só no projeto do MST. Mészáros (2006, p. 230) também entende que pode haver uma transformação radical da educação, que poderia deixar de ser "mero instrumento da hegemonia burguesa" e passar a ser um "órgão de autodesenvolvimento e automediação consciente" que inspire os indivíduos a produzirem "segundo as suas verdadeiras capacidades humanas". É diante dessa questão que os educadores estão colocados. E aí, não podemos nos deter ao processo formal de educação, mas à educação como um sistema de internalização. (MÉSZÁROS, 2005).

A figura a seguir sintetiza os elementos que compõem a atual proposta pedagógica das escolas itinerantes do Paraná, em que as unidades curriculares são os complexos de estudo. Como podemos ver, cada Complexo de Estudo que tem sustentação em determinada concepção de educação, com determinados objetivos, vinculada à atualidade, é composto dos seguintes elementos: bases das ciências e das artes (com respectivos objetivos, conteúdos e êxitos esperados); objetivos formativos (e êxitos esperados); aspectos da realidade; trabalho socialmente necessário; métodos e tempos específicos; organização coletiva com auto-organização dos estudantes e fontes educativas.

Nessa proposta a conexão dos conteúdos com as questões da realidade tem centralidade, pois implica num processo de luta a tomada de consciência da realidade, diante da qual se exige um posicionamento, bem como o acesso aos conhecimentos produzidos histórica e socialmente, que representam um instrumento de luta e de qualificação desse posicionamento.

Outro aspecto que tem centralidade diz respeito à mudança da forma da escola, à alteração das relações lá estabelecidas, portanto, à mudança da gestão que passa a exigir a horizontalização das relações, a educação para a autogestão e a ampliação da participação nas decisões sobre o processo pedagógico. Assim, o MST propõe estratégias de auto-organização dos estudantes em várias direções: no que tange à participação mais efetiva no próprio processo de ensino, o que exige a consolidação de metodologias ativas e participativas, organizando-os em Núcleos Setoriais que os insiram no trato de questões importantes em cada local, desde o embelezamento dos espaços até questões políticas, culturais e outras. Percebemos que essa forma de organização supera àquela dos Grêmios Estudantis, que era baseada na educação para a democracia representativa. $\mathrm{Na}$ 


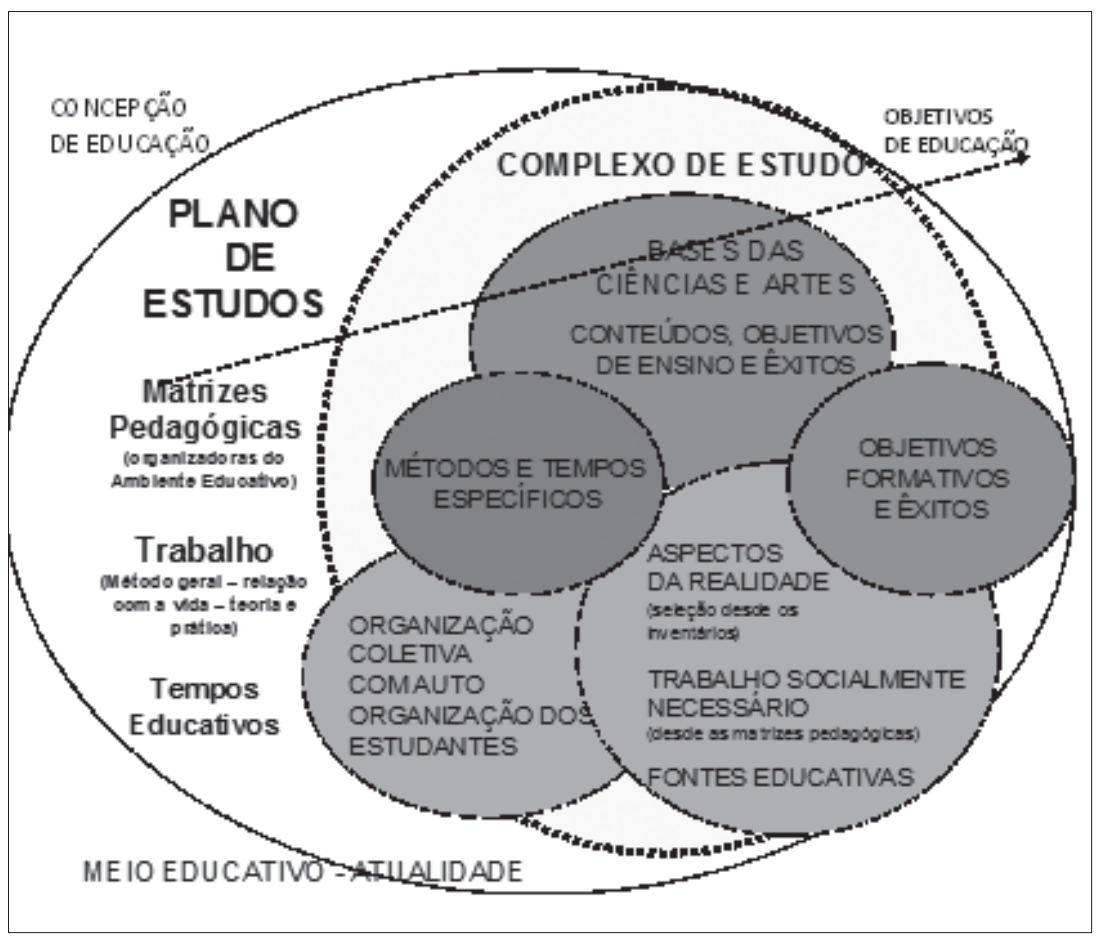

FONTE: Freitas, Sapelli e Caldart (2013).

proposta em questão, não se trata de participação por representação, pois a instância máxima é a Assembleia de todos os estudantes, portanto, participação efetiva.

No processo de implementação da proposta reconstruída, após a incorporação de mais elementos da pedagogia soviética, o Movimento tem enfrentado dificuldades relativas a várias questões. Uma delas diz respeito à rotatividade de professores. A cada ano há a troca de grande parte dos professores, o que dificulta avançar na implementação, pois quando o educador compreende a proposta acaba saindo da escola e isso exige o reinício do processo com quase todo corpo docente. Como se trata de uma proposta que apresenta uma complexidade, a sua não compreensão também compromete a sua consolidação.

A proposta também exige um grande trabalho coletivo dos educadores entre si; dos educandos entre si; dos educadores com os educandos; dos educadores e educandos com a comunidade. Vários fatores inviabilizam esse processo. Um deles é a cultura do individualismo muito cristalizada nas relações construídas 
FIGURA 2 - ESQUEMA DA PROPOSTA DE AUTO-ORGANIZAÇÃO DOS ESTUDANTES NA ORGANIZAÇÃO POLÍTICA DA ESCOLA

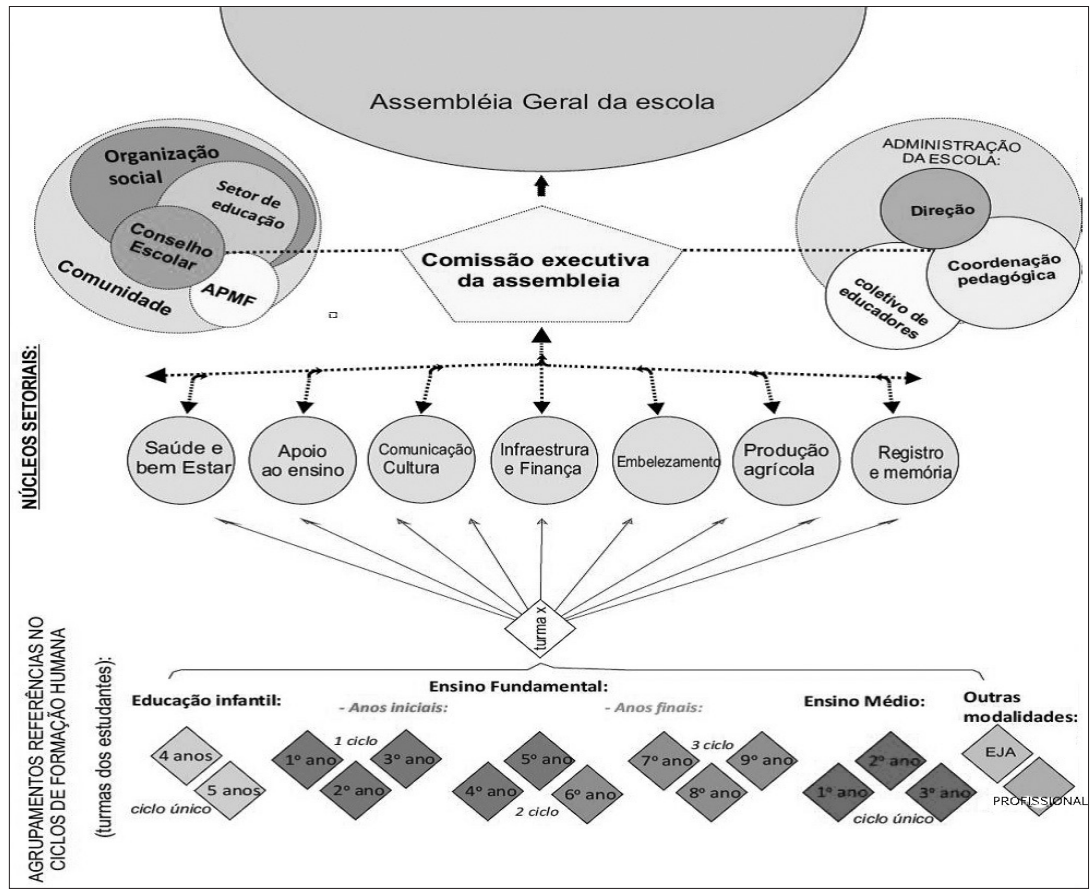

FONTE: Freitas, Sapelli, Caldart (2013).

no ambiente escolar, historicamente. Outro fator é que o trabalho coletivo acaba expondo as fragilidades de cada um, o que pode criar constrangimento para alguns que preferem manter-se no isolamento.

Faz-se necessário, para aderir à proposta, um claro posicionamento político no sentido de potencializar a classe trabalhadora enquanto classe para si. Nem todos os educadores envolvidos têm esse posicionamento. Apesar de serem da classe trabalhadora, alguns educadores se identificam mais com a classe que o explora do que com sua própria classe, portanto, não se dispõem a construir uma proposta educativa na perspectiva da emancipação humana. Faz parte de uma classe, mas se coloca a serviço de outra. Esse posicionamento representa uma dificuldade no processo de implementação da proposta.

A proposta também exige um processo de formação continuada dos educadores envolvidos na implementação, mas há dificuldades de encontrar fontes de financiamento para esse processo. A formação continuada nesse caso 
representa um processo de estudo e de aprofundamento para entender os fundamentos e construir os encaminhamentos teórico-metodológicos necessários à consolidação do Plano de Estudos.

Há ainda a necessidade, além da formação continuada centralizada, envolvendo todos os participantes, de um acompanhamento mais próximo, em cada local, para sanar as dúvidas que forem surgindo no processo. O Movimento conseguiu apoio de alguns educadores das Universidades parceiras e de algumas pessoas do setor estadual de educação do MST, mas esse acompanhamento tem sido muito pontual e esporádico.

Há resistência dos coletivos das escolas na mudança dos tempos e espaços em outra lógica, diferente daquela tradicionalmente existente nas escolas. Tirar a sala de aula do centro do processo exige romper com os horários pré-estabelecidos, com as atividades internas, exige potencializar o uso de fontes educativas da própria comunidade, exige ativar processos de trabalho socialmente necessários que não se expressam de forma suficiente nos processos de autosserviço já existentes nas comunidades.

Apesar das dificuldades no processo de implementação da proposta nesse primeiro ano, seria precipitada qualquer conclusão definitiva sobre as potencialidades da mesma. As dificuldades indicam, de certa forma, a rigidez da forma escolar atual, portanto, os desafios para encontrar alternativas eficazes para mudanças estruturais.

Observando e participando do processo de constituição das escolas itinerantes, há 11 anos, podemos perceber claramente a contradição que existe entre o velho e o novo jeito de educar, ou seja, entre a proposta de educação capitalista e socialista. Segundo Mészáros (2007, p. 294), a educação capitalista representa uma "[...] doutrinação da esmagadora maioria das pessoas com os valores da ordem social do capital"; é definida do ponto de vista do capital; tem como centralidade o desenvolvimento dos indivíduos particulares; serve à expansão do capital; e a educação socialista tem papel desmistificador; tem por objetivo o "[...] desenvolvimento contínuo da consciência socialista na sociedade como um todo" (MÉSZÁROS, 2007, p. 298); é definida do ponto de vista do trabalho; tem como preocupação educar para a coletividade; deve estar articulada a uma intervenção consciente e efetiva no processo de transformação social; serve à ampliação da riqueza social; “[...] deve ser capaz de confrontar e retificar conscientemente as relações sociorreprodutivas estruturalmente resguardadas" (MÉSZÁROS, 2007, p. 306); implica na autoeducação radical dos indivíduos sociais.

Há um esforço significativo dos educadores e das comunidades das escolas itinerantes no sentido de superar a educação capitalista, mas ainda há elementos que a caracterizam, presentes nas práticas pedagógicas realizadas nas mes- 
mas. Mesmo assim, já é possível visualizar elementos da educação socialista, especialmente os relacionados à educação para a coletividade e à intervenção consciente e efetiva no processo de transformação social, pois há uma íntima relação entre a proposta de educação, considerada tática para o engendramento do projeto estratégico de sociedade.

\section{Considerações finais}

Se em alguns momentos o MST foi acusado de ter como central a luta pelo direito de acesso à educação formal, portanto, de atuar no limite do Estado de direito, o atual processo e a luta pela mudança da forma e do conteúdo da educação, como tática em um projeto estratégico maior, explicitam que as preocupações do Movimento, em relação aos processos educativos, não se limitam ao acesso à educação formal, mas apresentam elementos que transcendem o próprio espaço escolar. Portanto, indicam a necessidade de se potencializar processos educativos formais e não formais no compromisso com a formação humana omnilateral e também de romper com o tradicional conteúdo e forma escolar.

Esse primeiro momento de implementação da proposta reformulada pelo MST para as escolas itinerantes e para a escola-base indica mais avanços teóricos do que na prática pedagógica. Mesmo assim, representa um exercício de construção de proposta curricular própria, portanto, um exercício de autogestão, tão necessário na atual conjuntura, na qual a educação está submetida ao projeto neoliberal de sociedade e se expressa em políticas educacionais de privatização do conhecimento, de precarização dos processos escolares da classe trabalhadora, de centralização das decisões acerca do currículo e da gestão das escolas, engendradas pelo Estado, a serviço da classe dominante. Esse exercício representa também um processo de protagonismo e controle social feito pela classe trabalhadora no âmbito da educação pública.

E para concluir, voltamos ao título Escola itinerante: espaço de disputa e contradição. O que está em disputa? Certamente, o que está em disputa é a educação da classe trabalhadora que pode ser engendrada para ser instrumento de uma classe que se constituiu enquanto classe para si ou de uma classe que se constituiu enquanto classe a serviço de outra, submetida às suas necessidades e limitada à exploração alienada e degradante.

Que contradições ela apresenta? $\mathrm{Na}$ escola atual convivem o velho e novo jeito de se educar, o velho que resiste em se manter e o novo que nasce do velho, mas precisa ser a superação do mesmo; convivem os que compreendem 
claramente o papel da escola, que deve se posicionar no processo de luta de classes a favor da classe trabalhadora na perspectiva da sua emancipação, e os que compreendem que o posicionamento deve ser a favor da manutenção do atual processo; há uma tensão entre o movimento social e o Estado, cada qual defendendo os interesses da classe que os orienta; há um confronto entre os proprietários e não proprietários na luta pela terra; há ainda um esforço de superação dos processos de regulação e de construção de processos de autogestão.

Essa constatação deve nos levar a compreender a importância de potencializar experiências de autogestão e de controle social no âmbito da escola pública, como essa consolidada, mesmo que com muitos limites, pelo Movimento dos Trabalhadores Rurais Sem Terra.

\section{REFERÊNCIAS}

CAMINI, Isabela. Escola itinerante na fronteira de uma nova escola. São Paulo: Expressão Popular, 2009.

CERICATO, Kátia Aparecida Seganfredo. Os princípios organizativos e a proposta pedagógica do MST: contradições de sua materialização na Escola Estadual Iraci Salete Strozak. 210 p. Dissertação (Mestrado em Educação) - Universidade Estadual de Londrina, Londrina, 2008.

DATALUTA. Banco de dados da luta pela terra. Relatório 2006. Coordenação Geral Bernardo Mançano Fernandes. Disponível em <http://cac-php.unioeste.br/projetos/ geolutas/projetos_dataluta_relatorios.php>. Acesso em: 31 maio 2011.

FREITAS, L. C.; CALDART, R. S.; SAPELLI, M. L. S. (Orgs.). Plano de Estudos da Escola Itinerante. Cascavel: Edunioste, 2013.

LEINEKER, Mariulce da Silva Lima. Escolas do campo no Paraná: entre a conquista e a imposição. 194 p. Dissertação (Mestrado em Educação) - Universidade Federal do Paraná, Curitiba, 2012.

MÉSZÁROS, István. A educação para além do capital. Trad. Isa Tavares. São Paulo: Boitempo, 2005.

MÉSZÁROS, István. A teoria da alienação em Marx. Trad. Isa Tavares. São Paulo: Boitempo, 2006.

MÉSZÁROS, István. O desafio e o fardo do tempo histórico. São Paulo: Boitempo, 2007.

MST. Dossiê MST Escola. Documentos e estudos 1990-2001. Veranópolis: Iterra, 2005. 
MST. Escola Itinerante do MST: história, projeto e experiências. Caderno da Escola Itinerante - MST, Curitiba: SEED, Ano VIII, n. 1, abr. 2008a.

MST. Itinerante: a escola dos Sem Terra - trajetórias e significados. Cadernos da Escola Itinerante - MST, Curitiba: SEED, Ano I, n. 2, out. 2008b.

MST. Organização da Escola Itinerante de Educação Infantil ao Ensino Médio. Curitiba, 2006. (mimeo).

PISTRAK, Moisey Mikhailovich. Fundamentos da escola do trabalho. Trad. Daniel Aarão Reis Filho. 3. ed. São Paulo: Expressão Popular, 2003.

PISTRAK, Moisey Mikhailovich. (Org.). A Escola-comuna. Trad. Luiz Carlos de Freitas e Alexandra Marenich. São Paulo: Expressão Popular, 2009.

SAPELLI, Marlene L. S. Escola do Campo - Espaço de disputa e de contradição: análise da Proposta Pedagógica das Escolas Itinerantes do Paraná e do Colégio Imperatriz Dona Leopoldina. 331p. Tese (Doutorado) - Programa de Pós-Graduação da Universidade Federal de Santa Catarina, Florianópolis, 2013.

SHULGIN, Viktor Nikholae Vich. Rumo ao politecnismo. Tradução de: Alexey Lazarev e Luiz Carlos de Freitas. São Paulo: Expressão Popular, 2013.

TSÉ-TUNG, Mao. Sobre a prática e sobre a contradição. São Paulo: Expressão Popular, 2001.

Texto recebido em 12 de fevereiro de 2015.

Texto aprovado em 04 de março de 2015. 
